\title{
Cast Aluminum Composite Obtained by Using Ultrafine Carbon Raw Materials
}

\section{Lezhnev $\mathbf{S}^{1 *}$, Kuis $D^{2}$, Volochko $A^{3}$, Shegidevich $A^{3}$, Svidunovich $\mathbf{N}^{2}$ and Naizabekov $A^{4}$}

${ }^{1}$ Karaganda State Industrial University, Kazakhstan

${ }^{2}$ Department of Material Science and Metal Technology, Belarusian State Technological University, Belarus

${ }^{3}$ Physical-Technical Institute of National Academy of Sciences of Belarus, Laboratory Microcrystalline and Amorphous Materials, Belarus

${ }^{4}$ Rudny Industrial Institute, Kazakhstan

\begin{abstract}
The paper presents the casting-deforming technology intended to produce cast aluminum composites and items from them (in-situ technology). In addition the investigation has been made of the effect of mechanical activation of a charge containing these carbon forms as well as of intensive plastic deformation on the possibility of their structure rearrangement and creation of new forms (glass carbon and diamond-like carbon particles) with the aim of their use in in-situ casting technologies.
\end{abstract}

Keywords: Composite materials; Carbon raw materials

\section{Introduction}

Nowadays a special R\&D attention is focused on novel fast-evolving technologies associated with the demand for production of generalpurpose materials with advanced properties that are particularly promising for application in various industries. This exactly refers to investigations in the area of creating materials with enhanced physical, mechanical and performance characteristics and explains interest in metal based composites and specifically in their cast aluminum and titanium versions with modified structure and hardened by different fillers $[1,2]$.

Currently great interest is being shown in investigations devoted to finding new carbon structure forms such as grapheme, fullerene and nanotubes as well as in their use for development of new materials. However, depending on the total content of impurities, surface chemistry, etc., their cost can be varied up to thousands of dollars per a gram which certainly restrains their use especially when producing general-purpose composite materials.

In this study the attempt is made to assess the possibility of using combined nano-carbon forms such as fullerene blacks for development of aluminum composites with desired properties.

\section{Testing Procedures}

To obtain test samples of cast aluminum composite processed by ligature containing glass carbon phase the use has been made of castingdeforming technological method [3]. The method involves stirring of powder charge components and carrying out of mechanical activation of resulting mixture with obtaining a ligature and production by casting of composite materials based on aluminum matrix (Figure 1).

The samples of ligatures were prepared from aluminum powders with particle sizes of the main fraction equal to 5-100 $\mu \mathrm{m}$ or from ground chips of AK9 alloy and some nanocarbon materials (fullerenecontaining soot, fullerenes $\mathrm{C}_{60}$, fullerene niello) in the proportion: $\mathrm{Al}$ 10 mass $\% \mathrm{C}$ in the initial mixture. Fullerene fullerene blacks produced by Yoffe Physical-technical Institute of Russian Academy of Sciences, St.-Petersburg were used as carbon nanomaterials.

To produce the suggested cast aluminum composite processed by ligature containing glass carbon phase the AK9ч alloy was taken as a base one. The ligature was incorporated at the melt heating temperature of $750-780^{\circ} \mathrm{C}$ and the time of ligature melting was $3-5 \mathrm{~min}$. The amount of composite material incorporated into melt was one tenth part of the whole composition. The temperature was controlled by the multichannel recorder PMT 39D connected to PC.

The billets ( $\varnothing 40 \mathrm{~mm}, \mathrm{~h}=180 \mathrm{~mm}$ ) to be investigated were made in metal chill mold at the cooling temperature of $40-50^{\circ} \mathrm{C} / \mathrm{s}$. The obtained billets were used for preparing samples for hardness, strength, friction, wear and relative elongation tests.

The antifriction properties were investigated on the friction test machine УMT 2 under the following conditions of cycling oil feeding (oil МГ-10T): 1 droplet in $10 \mathrm{~s}$ during end friction. The 40X steel was used as a counterbody. The temperature of a friction zone did not exceed $220-250^{\circ} \mathrm{C}$. The bearing capacity of a friction pair was 450 $480 \mathrm{MPa} \cdot \mathrm{m} / \mathrm{s}$.

The morphology and microstructure of samples were examined by the method of metallagraphic analysis using the complex Micro-200. The phase composition was identified with the aid of X-ray diffractometer D8 Advance, "Bruker", using the "X-RAY" programs of X-ray phase analysis automation. The combination light scattering

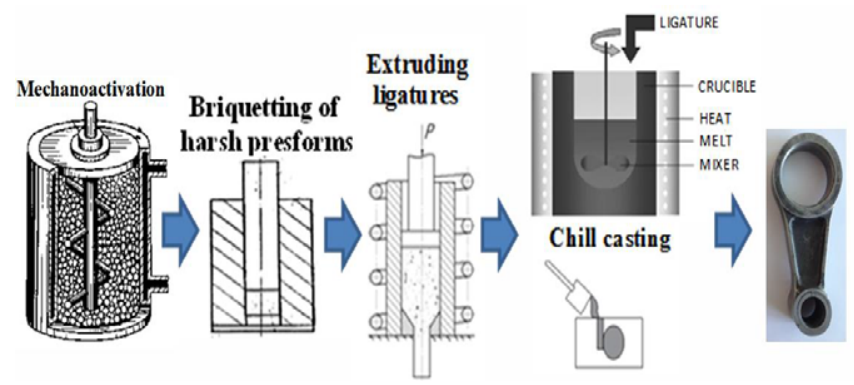

Figure 1: Casting-deforming technology of producing the cast aluminum composites and items from them.

*Corresponding author: Lezhnev S, Karaganda State Industrial University, Kazakhstan, Tel: +77017725358, E-mail: sergey_legnev@mail.ru

Received April 14, 2015; Accepted April 22, 2015; Published April 30, 2015

Citation: Lezhnev S, Kuis D, Volochko A, Shegidevich A, Svidunovich N, et al. (2015) Cast Aluminum Composite Obtained by Using Ultrafine Carbon Raw Materials. J Material Sci Eng 4: 166. doi:10.4172/2169-0022.1000166

Copyright: (c) 2015 Lezhnev S, et al. This is an open-access article distributed under the terms of the Creative Commons Attribution License, which permits unrestricted use, distribution, and reproduction in any medium, provided the original author and source are credited. 
spectra were obtained using the combination scattering spectrometer RAMANOR U-1000, Jobyn Yvon Instruments S. A. Inc., equipped with a microscope. The laser excitation wavelength was $514 \mathrm{~nm}$ with spectrum resolution of $1 \mathrm{~cm}^{-1}$ and spatial resolution of $2 \mu \mathrm{m}$. The fine structure and microchemical composition of samples were investigated using the scanning electron microscope JSM-5610 LV with the system of qualitative and quantitative X-ray microspectrum analysis EDX, Jeol, (the elemental analysis was performed in a point, over the area in a graphical form and in the form of "X-Map" images) and by means of the transmission electron microscope, JEOL JEM 2100, at the accelerating voltage of $200 \mathrm{kV}$.

The Brinell hardness of samples was determined using the hardness meter TШ-2M at the load of $250 \mathrm{~kg}$, the ball diameter of $5.0 \mathrm{~mm}$ and the microhardness was measured with the microhardness meter Duramin Struers at 10-2000 g. The strength was measured on the tension-compression machine ZD-10/90 at the force of $10 \mathrm{kN}$.

\section{Discussion}

The ligature (Figure $2 \mathrm{a}$ and $2 \mathrm{~b}$ ) was prepared from an aluminum powder having particle size of the base fraction equal to 5-100 $\mu \mathrm{m}$ and form some nanocarbon materials (fullerene blacks) with the following initial mixture composition: Al-10 mass \% C.

In the process of production the particles of a grey globular-shape phase, Figure 3 were observed in ligature. They had a microhardness comparable with that of a diamond (Figure 4). Then, when examined by electron microscopy, X-ray diffraction and Raman spectroscopy these particles were identified as amorphous and similar to glass carbon Figure 5 [3]

When investigating the phase composition it has been established that quite insignificant quantity of a carbide component equal to $\approx 2-3$ mass $\%$ is found in silumin-based ligatures produced using nanocarbon materials such as fullerene blacks. This is in the range of error, has no detrimental effect on the material and in actual fact does not lead to initiation of its embrittlement. In contrast to this when a microcrystalline graphite is used the content of carbides amounts to 10-15 mass $\%$.

It should be noted that the microstructure of aluminum alloy after above-mentioned processing exhibits a uniform modification of all alloy constituents including an eutectic component. It was established that the eutectic silicon crystals were comminuted up to a four times lower particle size and the width of dendrites of $\alpha$ aluminum phase was decreased by a factor of 3-3.5 (Figure 6). That modifies the composite structure as a whole and improves its properties.

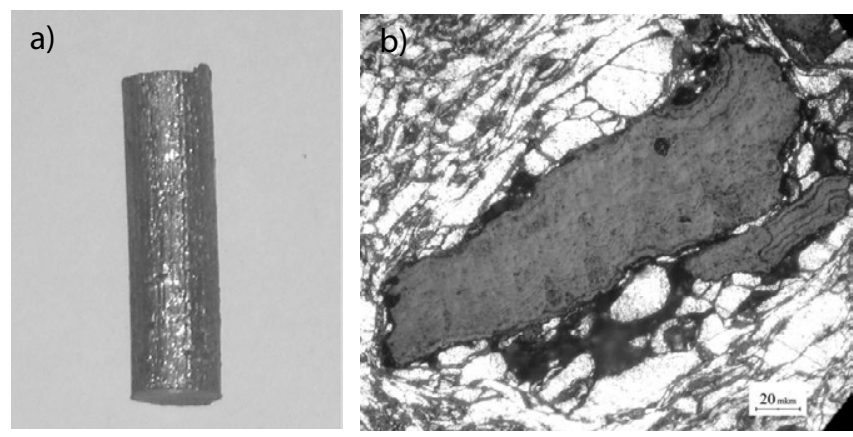

Figure 2: Ligature with particles of superhard amorphous carbon: (a) ligature (b) ligature microstructure with an amorphous glass carbon particle.

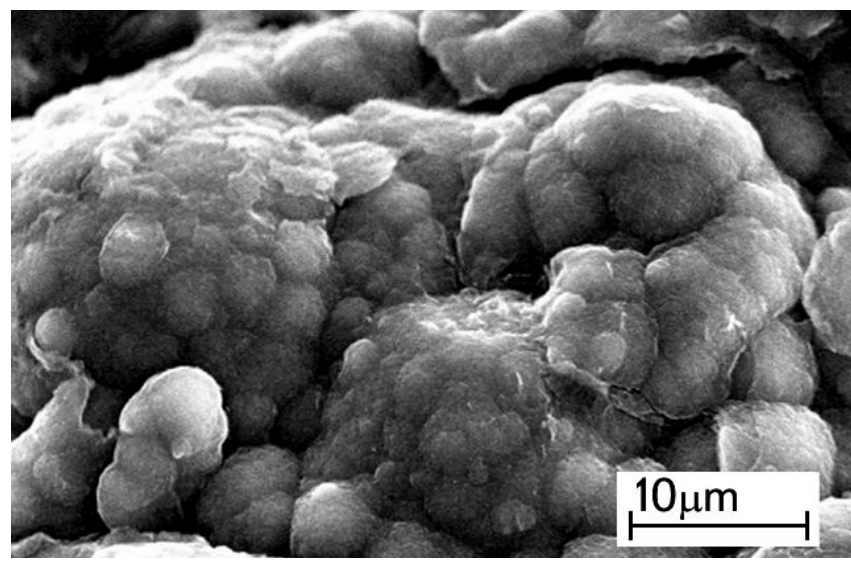

Figure 3: Globular structure of a glass phase.

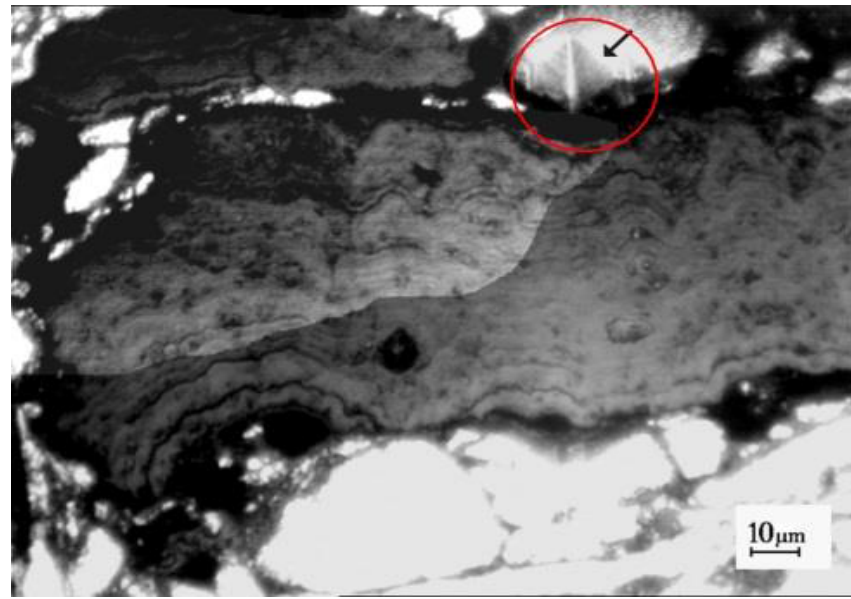

Figure 4: Microhardness ligature glass phase (indenter moves down from the particle surface of the arrows).
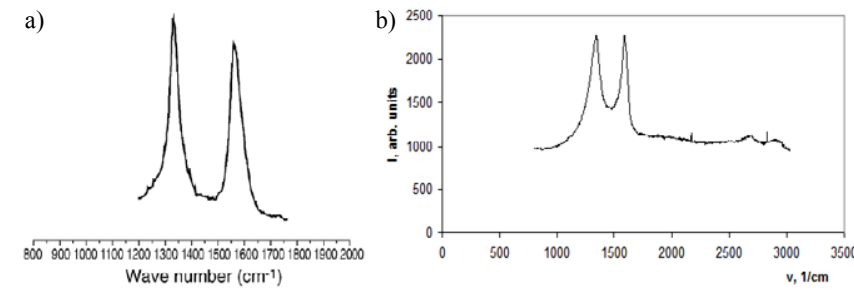

Figure 5: Raman spectra: (a) typical glassy carbon, (b) ligature glass phase.
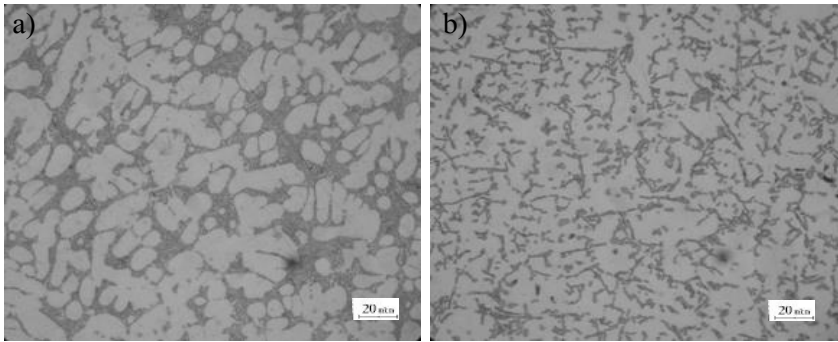

Figure 6: The alloy microstructure: (a) of initial AK9 silumin, (b) cast composite processed with use of ligature. 
Citation: Lezhnev S, Kuis D, Volochko A, Shegidevich A, Svidunovich N, et al. (2015) Cast Aluminum Composite Obtained by Using Ultrafine Carbon Raw Materials. J Material Sci Eng 4: 166. doi:10.4172/2169-0022.1000166

Page 3 of 3

As compared to an initial silumin the strength of a cast composite was enhanced and was nearly $450 \mathrm{MPa}$ at increased temperatures, the hardness was increased about 1.5 times and reached the value of 110 $\mathrm{HB}$ and the wear resistance was increased 2 times. In this case plastic characteristics are indicative of the possibility of a further plastic deformation of cast billets $(\delta=8-10 \%)$. Presence of carbon inclusions in microstructure favored decrease of the coefficient of friction 1.9 times from 0.52 to 0.28 after one-hour testing.

\section{Conclusions}

Thus, the stages studied the structural state and properties of cast aluminum composites obtained using of ultrafine carbon raw materials. This research haven't revealed fundamental differences in the formation of ligatures $\mathrm{Al}-\mathrm{C}$, obtained with the use of expensive fullerenes, in comparison with the alloys obtained using cheaper nanocarbon materials. The results of mechanical tests also confirmed that the use of ultrafine carbonaceous materials in the processing of aluminum melt allows obtaining high-quality composite materials, which have high strength characteristics in plastic indicators to expose these composite materials are further processed (plastic deformation). This combination of strength and plastic characteristics of these composite materials makes them promising for industrial development. The obtained composite materials can find wide application when developing items that possess high technical characteristics and can be used for fabrication of precision machine-building parts designed for operation under friction and increased load-bearing conditions.

\section{References}

1. Ye X, Liu T, Ye Y (2015) Enhanced grain refinement and microhardness of TiAl-V alloy by electropulsing ultrasonic shock. Journal of Alloys and Compounds 621: $66-70$.

2. Ye X, Yang Y, Tang G (2014) Microhardness and corrosion behavior of surface gradient oxide coating on the titanium alloy strips under high energy electropulsing treatment. Surface and Coatings Technology 258: 467-484.

3. Volochko AT (2006) Reprocessing and use of aluminum wastes on production of powders, pastes, composite and ceramic materials. Minsk: Belarus Navuka. 